\title{
Oil Sorption behavior of Nettle /Kapok blended Nonwoven Fabrics
}

\author{
M. Damayanthi \\ \{svn.textile@psgtech.ac.in $\left.{ }^{1}\right\}$ \\ Department of Textile Technology, PSG College of Technology, Coimbatore-641004, Tamil Nadu, \\ India $^{1}$
}

\begin{abstract}
Kapok fibers are significantly hydrophobic fiber and do not get with water. The main difficulty in the process is the inability to make a structure out of kapok fiber. So, Kapok fiber is blended with nettle fiber, which also proved to be good oil sorbent. Needle punched nonwovens from nettle and kapok fibrous webs of varying proportions are made. The nonwovens samples prepared were with $100 \%$ nettle, Nettle/Kapok 85/15, Nettle/Kapok 70/30 and Nettle/Kapok 50/50. Among all the samples, Nettle/Kapok $70 / 30$ blended nonwovens proved to be the best oil sorbent with high oil absorption rate and oil recovery $\%$ with structural integrity till 3 times of use.
\end{abstract}

Keywords: nettle, kapok, oil sorption, nonwoven fabric.

\section{Introduction}

Oil spill contamination, a harsh ecological trouble throughout the globe, is rising with increased levels of oil manufacture and transportation. Causes are either due to accident or owing to operation. Oil spill cleanup is a complex process. Elimination of oil by absorption is one of the main approaches for complete elimination of oil in ambient conditions. Oil spill cleanup has traditionally relied on skimmers, dispersants, gelling agents, and sorbents. Because of their particular properties, sorbent materials are commonly regarded as the most effective for oil spill cleanup [1]. Inorganic mineral materials, synthetic organic polymers, and organic natural materials can all be categorized as sorbent materials. Silica, graphite, organic clay, fly ash, vermiculite, zeolites, and perlite are only a few of the inorganic mineral elements. Synthetic organic sorbents such as polypropylene, polyethylene, and polyacrylate are common in oil spill cleanup [2,3].

High sorption capacity, hydrophobicity, high sorption rate, high retention capacity, mechanical qualities, reusability and biodegradability are all characteristics of desirable oil sorbents $[4,5]$. However, obtaining perfect oil sorbents that match all of the above characteristics remains a difficulty. Natural fiber based sorbents present considerable advantages including optimum mechanical properties, low density, stiffness and disposability. In addition, natural fiber based sorbents are biodegradable and recyclable. Hence, this study was intended to produce a low cost effective, ecological sorbent from country's available natural fibres.

Natural fibers namely kapok, flax, banana, nettle, coir were chosen for the study of oil absorbency. Preliminary testing of the fibers for their oil absorbency was done. The fibers showing higher oil absorbency property were selected for oil absorbent pad manufacturing. 
The fiber blend proportion was varied to make various products and their oil absorbency is tested.

\section{Materials And Methods}

\subsection{Kapok web formation}

Kapok fiber is made into web by several attempts of passage through roller clearer carding machine. Slow speed of the rollers is set to obtain the web. The feed roller speed was $1.00 \mathrm{rpm}$ and delivery roller speed was $2.85 \mathrm{rpm}$. The Figure 1 shows the Kapok fiber web

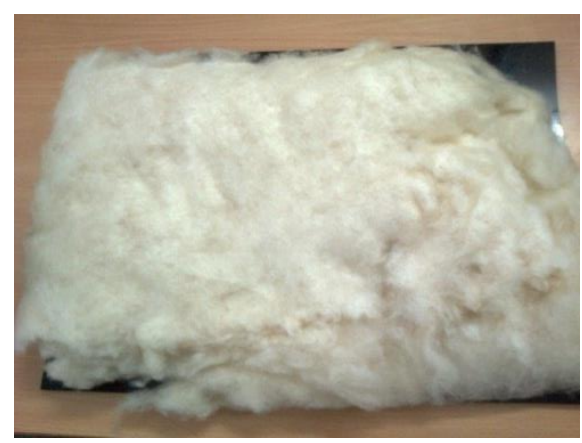

Fig. 1 Kapok fiber web

\subsection{Nonwoven preparation from kapok}

The Kapok fiber web is tried for needle punching. The kapok fiber due to low fiber length (10-20 mm) could not be processed in needle punching machine. Trials for chemical bonding also were undertaken. The kapok fibrous web is sprayed with adhesive chemical and dried in hot air oven. Bonding of fibers occurred in surface of the web only due to lack of water absorbency of kapok and waxy covering. Adhesive chemical may also affect oil absorbency of kapok. The Figure 2 shows the chemical bonded nonwovens.

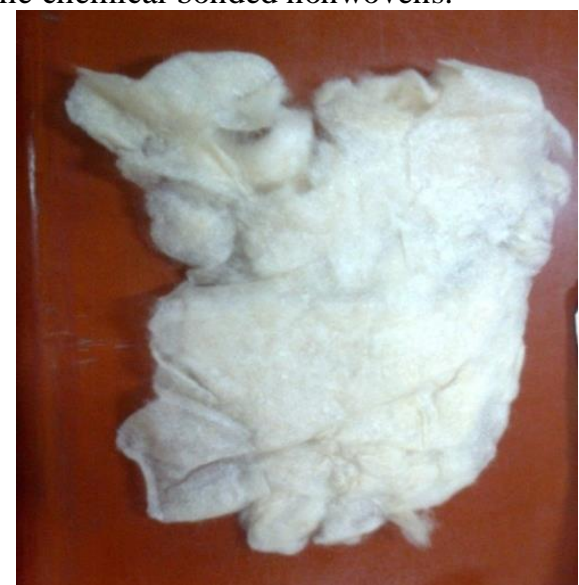

Fig.2 Chemical bonded nonwoven 


\subsection{Blending of fibers and web formation}

Blending of another oil absorbent fiber with kapok was done to achieve sufficient fiber properties for nonwoven manufacturing. The oil absorption capacity order of fibers showed that nettle fiber and banana fibers are comparably better than other fibers. So, attempts to make web out of 50/50 nettle/ kapok and 50/50 banana/kapok fibers were undertaken. Nettle/kapok blend yielded a continuous web. Banana/Kapok blend (due to brittle nature of banana fiber) yielded a discontinuous web. So, Nettle / Kapok blend is preferred for needle punching process and oil absorbency study. Figure 3 shows the Kapok/nettle blended web.

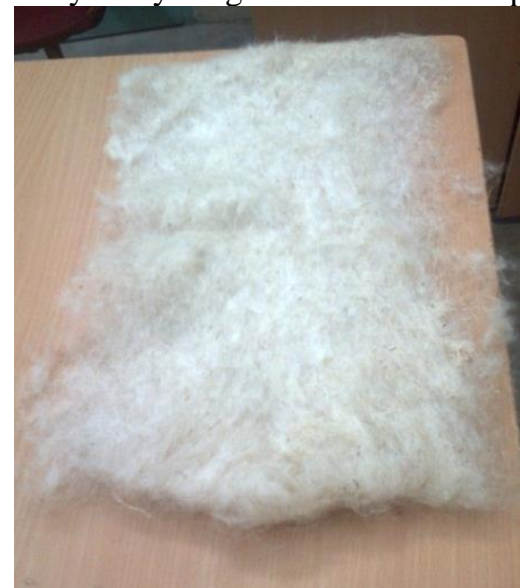

Fig.3 Kapok/nettle blended web

\subsection{Nettle/ kapok blended nonwoven manufacturing}

The Nettle/ Kapok blended webs with five various blend proportions were made in using the laboratory miniature Carding machine. The fine webs were built up into several layers in order to obtain desired level of fabric weight and thickness. The needle punching of webs were carried out in DILO needle-punching machine with depth of penetration of $8 \mathrm{~mm}$ and machine speed of $1 \mathrm{~m} / \mathrm{min}$. The nonwoven samples of varying weight and varying fibre blend proportions were made from laboratory miniature carding machine and needle punched using DILO needle-punching machine. $100 \%$ Kapok sample is made by quilting technique. The blend proportions are given in the Table 1

Table 1 Nonwoven samples

\begin{tabular}{|c|c|c|c|}
\hline \multirow{2}{*}{ S.No } & \multicolumn{2}{|c|}{ Composition } & \multirow{2}{*}{$\begin{array}{l}\text { Sample type } \\
\text { Needle punched nonwoven }\end{array}$} \\
\hline & Nettle & Kapok & \\
\hline 1 & 100 & 0 & Needle punched nonwoven \\
\hline 2 & 85 & 15 & Needle punched nonwoven \\
\hline 3 & 70 & 30 & Needle punched nonwoven \\
\hline 4 & 50 & 50 & Needle punched nonwoven \\
\hline 5 & 0 & 100 & Quilted sample \\
\hline
\end{tabular}




\subsection{Quilted sample specifications}

The Kapok is a short fiber with 1-2.5 cm length and is of brittle nature. Hence, formation of $100 \%$ Kapok fiber web and needle punching is difficult. So, a quilted structure of $100 \%$ Kapok fiber with nylon mesh cover fabric is made with the following specifications. Figure 4 shows $100 \%$ kapok quilted structure

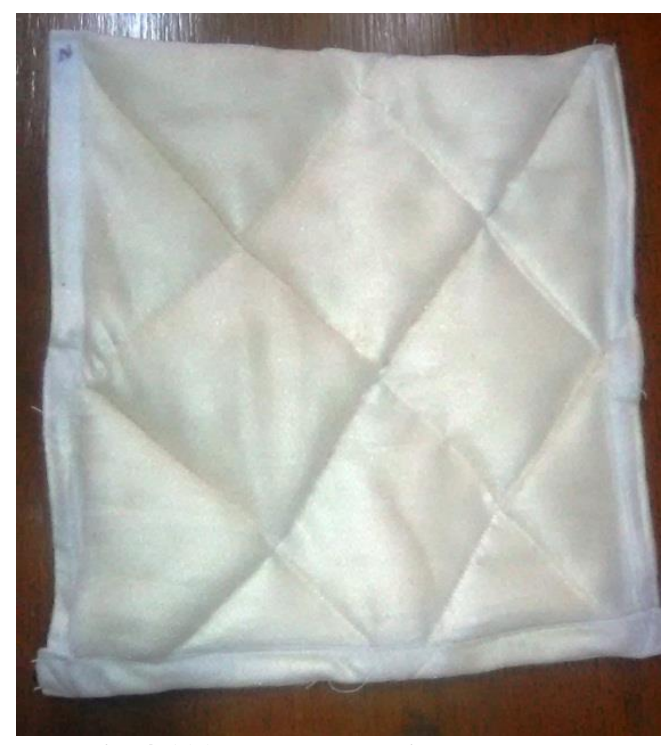

2.6 Testing of nonwoven fabric properties

Fibre lengths were measured with the help of standard scale by holding one end of the fibre fixed and moving the other end along the graduated scale. Fibre diameter values were calculated from the microscopical images of the fibers. Fiber fineness value in microns is obtained from the fiber diameter values. Average value is calculated from various fiber diameter values and corresponding fiber fineness value is derived. Fabric GSM was measured by cutting $5 \mathrm{~cm}$ X $5 \mathrm{~cm}$ pieces of fabric and weighing it on an electronic balance. Fabric thickness was measured by thickness tester of fabric and average value is calculated.

\subsection{Oil absorbency}

The adsorbent material was tested for oil absorbency using standard test method (ASTM F726 - 99). The oil absorbency of nonwovens till saturation was measured by saturation level test using oil (crude oil). The oil absorbency of nonwovens in presence of water was tested by standard oil absorbency test method using artificial sea water and crude oil. The known mass of the test sample is placed over test liquid (crude oil) in a beaker. After 10 minutes, the sample is lifted vertically above the test liquid level to allow the liquid to drip down for 30 seconds. Then the sample is weighed. The sample is tested for oil recovery by weighing the sample again after oil recovery (manual recovery). The same procedure is repeated again for 4 times to find the changes in oil absorbency rate and oil recovery\% with reuse.

\subsection{Oil/Water Absorbency}

The tray is filled with known volume of water to a height of at least twice the thickness of the sample. The test liquid (crude oil) is poured over the water level which is $8 \%$ of volume of 
water. Amount of test liquid taken is less than saturation level oil absorbency rate of nonwoven sample. The test sample of 10 " x 10 " size with known mass is placed over test liquid (crude oil). After 10 minutes, the sample is lifted vertically above the test liquid level to allow the liquid to drip down for 30 seconds. Then the sample is weighed. The sample is tested for oil recovery by weighing the sample again after oil recovery (manual recovery). The same procedure is repeated again for 2 times to find the changes in oil absorbency rate and oil recovery\% with reuse. As no oil remains above the water surface, the final volume of water after 3 times of absorbency is measured.

\section{Results And Discussion}

\subsection{Microscopical analysis}

The longitudinal view of nettle (Fig.5) and kapok fibers (Fig. 6) was examined under the optical microscope. The diameters of fibers were measured using the longitudinal view. Also, the oil absorbency of the fibers was examined visually using the optical microscope. Oil absorbency of $100 \%$ kapok was higher than $100 \%$ nettle fiber.

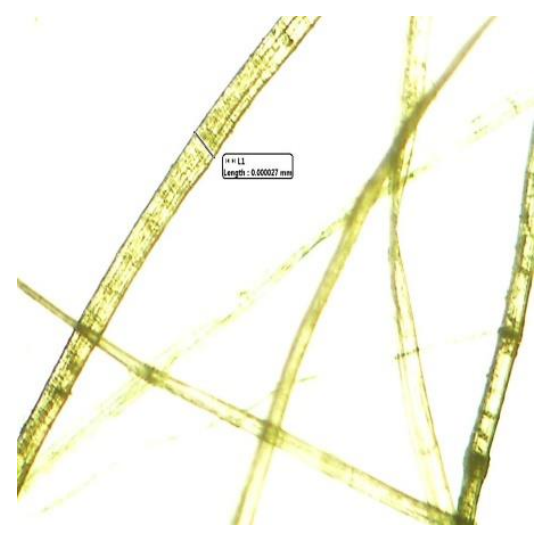

Figure 5. Longitudinal view of nettle fiber

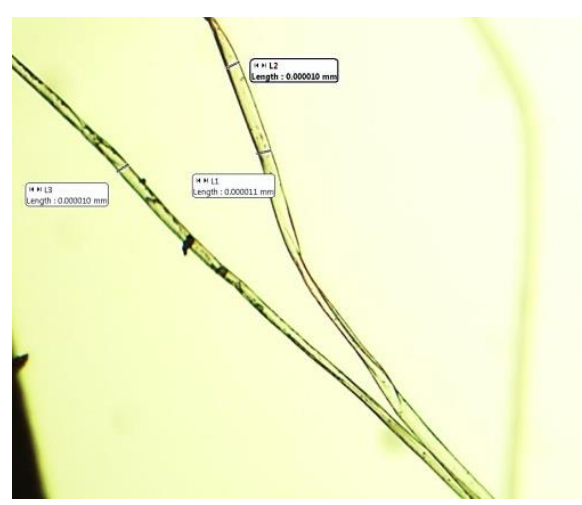

Figure 6. Longitudinal view of kapok fiber 


\subsection{Saturation level test}

Kapok shows highest oil absorption rate $(63.8 \mathrm{~g} / \mathrm{g})$ and oil recovery $\%$ than other blended nonwovens (Table 2). Ne/Ka 70/30 sample shows second highest oil Absorption rate (25.9 $\mathrm{g} / \mathrm{g}$ ). Oil recovery\% is almost equal among other blended nonwovens. Change in Oil absorption with reuse shows that during first reuse, the oil absorption rate becomes half the first usage for all nonwoven samples (Table 3). Oil Absorption rate decreases on second usage, then it increases and becomes nearly constant (low variation). Oil recovery\% increases on second usage, then it decreases and becomes nearly constant (low variation). When Oil absorption rate decreases, corresponding oil recovery increases.

Table 2. Oil absorbency rate with reuse

\begin{tabular}{|l|l|l|l|l|l|}
\hline Sample & 1st use $(\mathrm{g} / \mathrm{g})$ & 2nd use $(\mathrm{g} / \mathrm{g})$ & 3rd use $(\mathrm{g} / \mathrm{g})$ & 4th use $(\mathrm{g} / \mathrm{g})$ & 5th use $(\mathrm{g} / \mathrm{g})$ \\
\hline Nettle $100 \%$ & 15.68 & 8.2 & 9.13 & 8.18 & 7.43 \\
\hline $\begin{array}{l}\text { Nettle / Kapok } \\
85 / 15\end{array}$ & 15.76 & 6.51 & 7.78 & 7.95 & 8.51 \\
\hline $\begin{array}{l}\text { Nettle / Kapok } \\
70 / 30\end{array}$ & 25.91 & 12.37 & 17.66 & 18.29 & 17.54 \\
\hline $\begin{array}{l}\text { Nettle / Kapok } \\
50 / 50\end{array}$ & 14.58 & 5.67 & 8.42 & 8.48 & 8.19 \\
\hline Kapok 100\% & 63.84 & 29.26 & 11.09 & 17.88 & 18.53 \\
\hline
\end{tabular}

Table 3. Oil recovery $\%$ with reuse

\begin{tabular}{|l|l|l|l|l|l|}
\hline Sample & 1 st use (\%) & 2nd use (\%) & 3rd use (\%) & 4th use (\%) & 5 th use (\%) \\
\hline Nettle 100\% & $66 \%$ & $119 \%$ & $101 \%$ & $107 \%$ & $103 \%$ \\
\hline $\begin{array}{l}\text { Nettle / Kapok } \\
85 / 15\end{array}$ & $54 \%$ & $121 \%$ & $107 \%$ & $111 \%$ & $103 \%$ \\
\hline $\begin{array}{l}\text { Nettle / Kapok } \\
70 / 30\end{array}$ & $60 \%$ & $121 \%$ & $105 \%$ & $103 \%$ & $101 \%$ \\
\hline $\begin{array}{l}\text { Nettle / Kapok } \\
50 / 50\end{array}$ & $46 \%$ & $135 \%$ & $105 \%$ & $100 \%$ & $103 \%$ \\
\hline Kapok 100\% & $70 \%$ & $80 \%$ & $112 \%$ & $109 \%$ & $110 \%$ \\
\hline
\end{tabular}

\subsection{Oil absorbency in presence of water}

Oil absorption rate is highest for Nettle/Kapok 70/30 blend in all the three trials (Table 4). Kapok $100 \%$ shows low absorption rate and oil recovery\% which is due to the quilted structure formation. Oil absorption rate decreases with increasing number of trials except for Kapok $100 \%$ (Table 5). Oil Recovery\% is higher for Nettle 100\%.Oil recovery\% increases with reuse for all samples. Water absorption is of negligible quantity and is highest for $\mathrm{Ne} / \mathrm{Ka}$ $70 / 30$ ( $1.2 \%$ of initial water level). Reusability of nonwoven absorbent can be done upto 3 times with minimum structural distortions. 
Table 4.Oil absorbency in presence of water

\begin{tabular}{|l|l|l|l|}
\hline Sample & 1st use $(\mathrm{g} / \mathrm{g})$ & 2nd use $(\mathrm{g} / \mathrm{g})$ & 3rd use $(\mathrm{g} / \mathrm{g})$ \\
\hline Nettle $100 \%$ & 6.99 & 5.75 & 5.44 \\
\hline $\mathrm{Ne} / \mathrm{Ka} 85 / 15$ & 8.72 & 8.06 & 7.41 \\
\hline $\mathrm{Ne} / \mathrm{Ka} 70 / 30$ & 10.53 & 9.45 & 8.25 \\
\hline $\mathrm{Ne} / \mathrm{Ka} 50 / 50$ & 6.21 & 6.82 & 6.47 \\
\hline Kapok $100 \%$ & 5.21 & 5.3 & 5.3 \\
\hline
\end{tabular}

Table 5. Oil recovery $\%$ in presence of water

\begin{tabular}{|l|l|l|l|}
\hline Sample & 1 st use $(\%)$ & 2nd use $(\%)$ & 3rd use (\%) \\
\hline Nettle $100 \%$ & $79 \%$ & $92 \%$ & $95 \%$ \\
\hline $\mathrm{Ne} / \mathrm{Ka} 85 / 15$ & $71 \%$ & $93 \%$ & $90 \%$ \\
\hline $\mathrm{Ne} / \mathrm{Ka} 70 / 30$ & $71 \%$ & $94 \%$ & $94 \%$ \\
\hline $\mathrm{Ne} / \mathrm{Ka} 50 / 50$ & $52 \%$ & $91 \%$ & $91 \%$ \\
\hline Kapok $100 \%$ & $53 \%$ & $87 \%$ & $82 \%$ \\
\hline
\end{tabular}

\section{Conclusion}

The natural fibre possesses oil absorbency property. Kapok fiber shows an oil absorbency rate of $63.8 \mathrm{~g}$ oil $/ \mathrm{g}$ of fiber. The nonwovens oil sorbents were prepared from $100 \%$ nettle, Nettle/Kapok 85/15, Nettle/Kapok 70/30 and Nettle/Kapok 50/50. Among all the samples, Nettle/Kapok 70/30 blended nonwovens proved to be the best oil sorbent with high oil absorption rate and oil recovery \% with structural integrity till 3 times of use.

\section{References}

[1] Viju, S., and G. Thilagavathi. Oil spill cleanup by bonded nettle fibrous mat. Journal of the Institution of Engineers (India): Series E 100.1 (2019): 93-100.

[2] Chattopadhyay, D. P., and Varinder Kaur.Oil spill cleanup by textiles. Chapter 2 (2017): 27-41.

[3] Liu, Leigen, Zhenfeng Lin, Jiantao Niu, Dan Tian, and Jihuan He. "Electrospun polysulfone/poly (lactic acid) nanoporous fibrous mats for oil removal from water." Adsorption Science \& Technology 37, no. 5-6 (2019): 438-450.

[4] Viju, Subramoniapillai, Raju Seenivasan Rengasamy, Govindarajan Thilagavathi, Chandra Jeet Singh, and Haseeb Ahamed Kola Mohamed. "Sustainable development of needle punched nonwoven fabrics from silk worm cocoon waste for oil spill removal." Journal of Natural Fibers (2021): 1-11.

[5] R. Abirami, D.S. Vijayan, Sijo Joseph John, Aldrin Albert, and Alfred Koshy Alex, Experimental Study on Concrete Properties Using Pineapple Leaf Fiber, International Journal of Advanced Research in Engineering and Technology, 11(6), 2020, pp. 913-920, DOI: 10.34218/IJARET.11.6.2020.082 
$[6]$

[7] [6] Chau, Minh Quang, Tan Trung Truong, Anh Tuan Hoang, and Tri Hieu Le. "Oil spill cleanup by raw cellulose-based absorbents: a green and sustainable approach." Energy Sources, Part A: Recovery, Utilization, and Environmental Effects (2021): 1-14.

[8]

[9] Author AA. Title of book. Edition [if not first]. Place of publication: Publisher; Year of publication. Pagination. 